See discussions, stats, and author profiles for this publication at: https://www.researchgate.net/publication/326113727

\title{
Phloem-feeding herbivory on flowering melon plants enhances attraction of parasitoids by shifting floral to defensive volatiles
}

Article in Arthropod-Plant Interactions · July 2018

CITATIONS

0

9 authors, including:

(2) Patricia Sanches

University of São Paulo

7 PUBLICATIONS 34 CITATIONS

SEE PROFILE

Tiago Cardoso da Costa Lima

Brazilian Agricultural Research Corporation (EMBRAPA)

21 PUBLICATIONS 44 CITATIONS

SEE PROFILE
READS

205

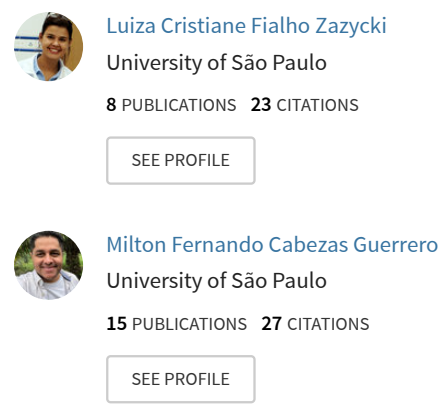

Some of the authors of this publication are also working on these related projects:

Pheromone of the pantropical ambrosia beetle Euplatypus parallelus (Curculionidae, Platypodinae) View project

Melon pest control tactics in the northeastern brazilian semiarid (Project funded by Embrapa) View project 


\title{
Phloem-feeding herbivory on flowering melon plants enhances attraction of parasitoids by shifting floral to defensive volatiles
}

\author{
T. A. Silveira ${ }^{1}$ P. A. Sanches ${ }^{2}$ (1) - L. C. F. Zazycki ${ }^{2}$ T. C. Costa-Lima ${ }^{3}$ (D) M. F. Cabezas-Guerrero ${ }^{2,4}$ - A. P. Favaris ${ }^{2}$ (1) \\ H. F. Goulart ${ }^{1} \mathbb{D}$. J. M. S. Bento ${ }^{2} \mathbb{D}$. A. E. G. Santana ${ }^{1} \mathbb{C}$
}

Received: 5 March 2018 / Accepted: 26 June 2018 / Published online: 2 July 2018

(C) Springer Nature B.V. 2018

\begin{abstract}
Emission of herbivore-induced plant volatiles (HIPVs) can differ according to the type of herbivory and the plant development stage, ultimately affecting recruitment of the natural enemy. Little is known about plant defenses induced at the flowering stage by phloem-feeding insects. We investigated the olfactory preference of Encarsia desantisi parasitoids and the chemical profile of flowering melon plants induced or not by the phloem-feeding of Bemisia tabaci whiteflies. In addition, we tested whether the parasitoids were attracted to synthetic defensive HIPVs, which mimicked whitefly-infested flowering melons. The parasitoids recognized volatiles from undamaged melons but preferred the scent of host-infested melons in olfactometry assays. Amounts of most individual volatiles did not differ between plant treatments; however, only whitefly-induced melons released methyl salicylate and tetradecane, compounds known to attract parasitoids. Interestingly, grouping volatiles by chemical classes revealed that whitefly-infested melon released larger amounts of monoterpenes and smaller amounts of benzenoids than undamaged melons, which might underlying the parasitoid attraction and indicate a possible trade-off between defensive and reproductive defenses at the melon flowering stage. Additionally, E. desantisi preferred the mix of synthetic and defensive HIPVs over hexane (control), opening a new avenue for further investigations in using olfactory lures for $B$. tabaci biological control. This study is the first report of induced defenses in melon plants and their mediation in a tritrophic interaction, as well as the first record of $E$. desantisi behavioral preference for HIPVs.
\end{abstract}

Keywords Biological control $\cdot$ Tritrophic interaction $\cdot$ Bemisia tabaci $\cdot$ Herbivore-induced plant volatiles $\cdot$ Encarsia parasitoid

Handling Editor: Jarmo Holopainen.

Electronic supplementary material The online version of this article (https://doi.org/10.1007/s11829-018-9625-x) contains supplementary material, which is available to authorized users.

\section{J. M. S. Bento}

jmsbento@usp.br

1 Agriculture Sciences Center, Federal University of Alagoas, Maceió, AL 57072-900, Brazil

2 Department of Entomology and Acarology, University of São Paulo, "Luiz de Queiroz" College of Agriculture (ESALQ/USP), Av. Pádua Dias, 11, P.O. Box 9, Piracicaba, SP, Brazil

3 Brazilian Agricultural Research Corporation (Embrapa Semiárido), Highway BR-428 Km 152, Petrolina, PE, Brazil

4 Present Address: Universidad Técnica Estatal de Quevedo, Facultad de Ciencias Agrarias, Campus "Ingeniero Manuel Agustín Haz Álvarez", Av. Quito, km 1 1/2 vía a Santo Domingo de los Tsáchilas, Quevedo, Ecuador

\section{Introduction}

Herbivore-induced plant volatiles (HIPVs) are chemical cues that attract the herbivores' natural enemies, thus indirectly aiding in plant defense (Turlings and Wäckers 2004; Kessler and Heil 2011). These plant emissions differ with feeding mode of herbivores, which affects the HIPV cues for natural enemies (Heil 2009; Bonaventure 2014). Extensive plant tissue damage triggers the octadecanoid pathway, which is orchestrated primarily by the phytohormone jasmonic acid (JA) (Koo and Howe 2009; Erb et al. 2012; Wasternack and Hause 2013). JA plays a central role in signal transduction of the HIPV emissions (Erb et al. 2012), thereby increasing the recruitment of natural enemies (Thaler et al. 2002; Bruinsma et al. 2009). Phloem-feeding insects, in contrast to chewing herbivores, do not injure plant tissues severely and consequently generally do not elicit JA defensive pathways. Rather, phloem sap-sucking insects activate salicylic-acid 
(SA) signaling, in the shikimate pathway, and suppress JAregulated defenses (Zarate et al. 2007; Zhang et al. 2013a), thus reducing emissions of JA-dependent volatiles (Zhang et al. 2013b). Therefore, parasitoids of phloem-feeding pests must use smaller amounts of HIPVs emitted in order to locate their host (Rodriguez-Saona et al. 2003; Walling 2008).

HIPVs might also differ among plant development stages of intact and herbivore-damaged plants (Lucas-Barbosa et al. 2011). Inducible indirect defenses are pronounced in plants at early stages, since their small leaves are especially susceptible to herbivory (Ohnmeiss and Baldwin 2000; McCall and Fordyce 2010). In contrast, mature and flowering plants must redirect energy from producing defensive compounds to producing reproductive tissues (Boege and Marquis 2005; Boege et al. 2007), in order to provide for pollinator recruitment and seed production (Kessler and Halitschke 2009; Lucas-Barbosa et al. 2011). As plants mature, this defensereproduction trade-off reduces the emission of defensive HIPVs and thus the plant's attractiveness to herbivores' natural enemies (Pareja et al. 2012; Schiestl et al. 2014; Desurmont et al. 2015). Since floral volatiles are benzenoids derived from the shikimate pathway (Dudareva and Pichersky 2006; Vogt 2010), attack by a phloem-feeding insect at the plant flowering stage would likely impact the HIPV cues available to natural enemies (Pareja et al. 2012).

Chemical dispensers that release synthetic HIPVs may be an alternative way to facilitate the recruitment of natural enemies when plants are emitting only small amounts of HIPVs (Khan et al. 2008; Gurr and Kvedaras 2010; Kaplan 2012). James (2003a) demonstrated that lures that released plant defensive HIPV compounds, such as green-leaf volatiles and methyl salicylate, were effective in recruiting natural enemies and helped to reduce insect-pest populations. However, most studies that have identified and tested the attractiveness of HIPVs to natural enemies have focused on predators or parasitoids of chewing insects that attack plants at the vegetative stages (James 2003b; Mallinger et al. 2011; Kelly et al. 2014; Jones et al. 2015). Only a few of these studies have examined how plants attract natural enemies of a phloem-feeding pest (James and Grasswitz 2005), especially crop plants in the reproductive phase (Yu et al. 2008; Mallinger et al. 2011).

Here, we investigated the olfactory response of the parasitic wasp Encarsia desantisi Viggiani (Hymenoptera: Aphelinidae) to herbivory by the whitefly Bemisia tabaci (Gennadius) (Hemiptera: Aleyrodidae) in flowering melon plants. We also assessed the parasitoid's preference for synthetic and defensive HIPVs, in order to evaluate the feasibility of volatile lures for recruitment of $E$. desantisi. The whitefly $B$. tabaci is one of the most important phloem-feeding insects and causes extensive crop damage worldwide (Stansly and Naranjo 2010; Li et al. 2011). Wasps of the genus Encarsia are thelytokous solitary endoparasitoids of whitefly nymphs (Hoddle et al. 1998; Liu et al. 2015) and have been used successfully to control B. tabaci populations in greenhouses (Arnó et al. 2009; Liu et al. 2015). To date, only a handful of studies have addressed features of E. desantisi, and the searching behavior of this wasp is largely unknown in spite of its wide distribution in South American crops, specifically using $B$. tabaci as the host (Heraty et al. 2008). We conducted olfactometer assays with $E$. desantisi, using sources of natural and synthetic odors, and we collected volatiles from undamaged and whitefly-infested melon plants at the flowering stage, in order to answer the following questions: (i) is the parasitoid $E$. desantisi attracted to host-induced volatiles in flowering melons during its host-searching behavior? (ii) does $B$. tabaci induce volatile-related defenses in flowering melon plants? (iii) is $E$. desantisi attracted to blends of synthetic defensive HIPVs that are similar to the volatile blend from host-infested plants? This study is the first investigation of the searching behavior of E. desantisi. This is also the first report of melon-plant defenses and the role of melon HIPVs in tritrophic interactions, contributing to the understanding of plant defense-reproduction trade-off strategies.

\section{Materials and methods}

\section{Plants and insects}

Melon plants (Cucumis melo, type Yellow, variety Mandacaru) were grown in plastic pots $(2 \mathrm{~L})$ with the organic substrate Basaplant ${ }^{\circledR}$ and fertilized with Osmocote ${ }^{\circledR}(10$ $\mathrm{N}: 10 \mathrm{P}: 10 \mathrm{~K})$. The plants were kept in a sealed, insect-free greenhouse under natural conditions of light, temperature and humidity $\left(18-35^{\circ} \mathrm{C}, \mathrm{RH} 40 \pm 10 \%\right)$ until the beginning of flowering (45 days old) and were then used in the experiments. The whitefly Bemisia tabaci was reared on 40- to 55-day-old melon plants. The parasitic wasps $E$. desantisi were collected in melon fields in Piracicaba, São Paulo, Brazil $\left(22^{\circ} 52^{\prime} 33^{\prime \prime} \mathrm{S}, 047^{\circ} 38^{\prime} 30^{\prime \prime} \mathrm{W}\right)$. Parasitoids were identified by the Biological Institute of Campinas and voucher specimens were deposited in the "Oscar Monte" Insect Collection (Campinas, São Paulo). Encarsia desantisi were reared on melon plants infested with third- to fourth-instar nymphs of B. tabaci. All insects were reared in greenhouses under natural abiotic conditions $\left(18-34{ }^{\circ} \mathrm{C}, \mathrm{RH} 40 \pm 10 \%\right)$. The experiments were conducted from July to December 2016, in Piracicaba, in the laboratory under controlled conditions $\left(23 \pm 2{ }^{\circ} \mathrm{C}, 50 \pm 10 \% \mathrm{RH}\right)$ and using supplemental light for plants (Philips Green Power tubular LED, 12L:12D, $120 \mu \mathrm{mol} \mathrm{m}^{-1} \mathrm{~s}^{-1}, 400-700 \mathrm{~nm}$ ). 


\section{Plant treatments}

Plant treatments consisted of undamaged and B. tabaciinfested melon plants. In order to use infested plants under conditions similar to those in the field, the plants used in the experiments bore mixed stages of $B$. tabaci (i.e., eggs, nymphs, and adults). We released 20 adult whiteflies (5-dayold females and males in equal proportions) into a cage $(60 \times 30 \times 40 \mathrm{~cm})$ containing a 45 -day-old melon plant. These plants, induced by the adults, were used after 15 days, when they bore the adults plus approximately $300 \mathrm{eggs}$ and 650 third- to fourth-instar nymphs. The undamaged plants were from the same batch as the infested ones, however without $B$. tabaci. Therefore, the plants used in all experiments were 60 days old.

\section{Olfactometer assays with melon plants}

We assessed the olfactory preference of $E$. desantisi for undamaged and $B$. tabaci-infested melon plants, using a four-arm olfactometer $(14 \times 14 \times 2 \mathrm{~cm})$. Newly emerged $E$. desantisi females were placed in individual test tubes, fed with honey for $24 \mathrm{~h}$, and then used in the olfactometer assay. The olfactometer was attached to an ARS Volatile Collection System (ARS, Gainesville, FL, USA). Filtered and humidified air was pumped through PTFE (polytetrafluoroethylene) tubes into sealed cylindrical glass chambers (43 $\mathrm{cm}$ high and $18 \mathrm{~cm}$ diameter) that contained the plants as odor sources, and then into the side arms of the olfactometer. The air flow was adjusted to $0.1 \mathrm{~L} \mathrm{~min}^{-1} \mathrm{arm}^{-1}$. The assays were conducted during the daytime, from 09:00 to $12: 00 \mathrm{~h}$ and $14: 00$ to $16: 00 \mathrm{~h}$, when the parasitoids were most active. The olfactometer was positioned horizontally and was rotated $90^{\circ}$ in each replicate to prevent side bias. A single naïve female wasp was released in the center of the olfactometer. We observed the olfactory behavior of each parasitoid wasp for $10 \mathrm{~min}$. During this period, we recorded the first choice (the first olfactometer quadrant entered by the wasp), the number of entries into each quadrant, and the wasp's residence time in each quadrant. The central quadrant was considered as insect no-choice. Each replicate consisted of the olfactory behavior of a single female. In each assay, the treatments were arranged randomly in the quadrants. We evaluated the preference of $E$. desantisi exposed to the following combinations: (i) blank vs. undamaged melon at a quadrant ratio of 3:1 (3 blanks and 1 quadrant with an undamaged melon plant); (ii) blank vs. infested melon plant at a quadrant ratio of $3: 1$, respectively; and (iii) blank vs. undamaged vs. infested melon plant at a quadrant ratio of $2: 1: 1$, respectively. We conducted a total of 50 trials, divided into three blocks, each block containing all treatment combinations.

\section{Plant volatile collection and analysis}

Undamaged and infested melon plants were sealed in individual polyester (PET) bags $(8 \mathrm{~L})$. The upper right end of the bag was connected to the ARS system described above, pumping in filtered and humidified air at $0.2 \mathrm{~L} \mathrm{~min}^{-1}$; the upper left end was coupled to a vacuum pump attached to filters with the adsorbent polymer Haysep® (30 mg, 80/100 mesh, Alltech Assoc.), which pulled air through the bag at a rate of $0.1 \mathrm{~L} \mathrm{~min}^{-1}$. We collected volatiles from six plants of each treatment for $24 \mathrm{~h}$, using a photoperiod of 12L:12D. The polymer filters were washed with $150 \mu \mathrm{L}$ of hexane and the extracts were placed in sealed glass vials, which were stored in a freezer at $-30{ }^{\circ} \mathrm{C}$ until analysis. We added $5 \mu \mathrm{L}$ of a $50 \mathrm{ng} \mu \mathrm{L}^{-1}$ nonyl acetate solution as internal standard to each sample. Samples were analyzed in an Shimadzu 2010 gas chromatograph (GC) equipped with a flame ionization detector (FID) and using an HP-1MS column (30 m $\times 0.25 \mathrm{~mm}$ ID, $0.25 \mu \mathrm{m}$ film thickness; Agilent Technologies, Santa Clara, CA, USA). Two microliters of each sample was injected into a splitless injector, with helium as carrier gas. Oven temperature was maintained at $40{ }^{\circ} \mathrm{C}$ for $5 \mathrm{~min}$, then increased at $5^{\circ} \mathrm{C} \min ^{-1}-150{ }^{\circ} \mathrm{C}$, held for

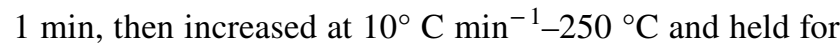
$20 \mathrm{~min}$. Each compound was quantified based on the compound peak area relative to nonyl acetate in the GC-FID. In order to characterize the compounds, samples were injected into a Shimadzu QP 2010 Ultra gas chromatograph coupled with a quadrupole mass spectrometer (GC-MS Quadrupole), adopting the same settings used for the GC-FID. Compounds were identified by calculating the Kovats index as well as comparing their mass spectra to the NIST 08 Mass Spectral Library (Sigma-Aldrich, St. Louis, MO, USA) and, when available, to those of the synthetic standards.

\section{Olfactometer assays with synthetic compounds}

We tested the attraction of $E$. desantisi to synthetic monoterpenes and alkane volatiles corresponding to those that were predominantly released by $B$. tabaci-infested melon plants, using a four-arm olfactometer, following the same method described above. A blend of synthetic compounds (all from Sigma-Aldrich, purity $>95 \%$ ) was prepared using $1 \mathrm{~mL}$ of hexane as solvent and each compound released by the plants, in the following concentrations: $\alpha$-pinene $\left(30 \mathrm{ng} \mathrm{mL}^{-1}\right)$, $\beta$-pinene ( $30 \mathrm{ng} \mathrm{mL}^{-1}$ ), $\beta$-myrcene ( $30 \mathrm{ng} \mathrm{mL}^{-1}$ ), $\beta$-ocimene (30 $\mathrm{ng} \mathrm{mL}^{-1}$ ), methyl salicylate $\left(10 \mathrm{ng} \mathrm{mL}^{-1}\right.$ ), and tetradecane $\left(20 \mathrm{ng} \mathrm{mL}^{-1}\right)$. For each trial, a wad of dental cotton was impregnated with $10 \mu \mathrm{L}$ of the synthetic-compound blend or with only hexane (control), left to evaporate for $10 \mathrm{~min}$, and then inserted into one of the olfactometer side-arm connectors. The treatments were arranged randomly in the quarters, at a treatment:quadrant ratio of 2:2. Each replicate consisted 
of observing the olfactory preference of a single female, for a total of 30 trials divided into two blocks.

\section{Statistical analyses}

In the olfactometer assays, arms containing the same treatment were grouped and their hypothetical probabilities of occurrence were combined. The parasitoids' first choice and the proportion of parasitoids entering the arms with odors were analyzed by binomial test when comparing two treatments (blank vs. undamaged or blank vs. infested plants) and by multinomial test when comparing three treatments (blank vs. undamaged vs. infested plants) with the null hypothesis $\mathrm{H}_{0}$ that each olfactometer arm has an equal probability of being chosen. The wasps' residence time in the olfactometer quarters was assessed by Friedman's two-way test, considering odor treatments as factors. A significant Friedman's test was followed by a Wilcoxon's test with Bonferroni's correction for multiple comparisons. Quantifications of the individual melon compounds, volatiles grouped by chemical class, and total emissions were evaluated with the non-parametric Wilcoxon signed-rank test. Additionally, the plant volatiles combined by chemical class were submitted to a Principal Components Analysis (PCA) based on Pearson's correlations, to account for relationships among compound groups. All data analyses from plant volatiles were evaluated in Minitab® Release 14 (Minitab Inc., State College, PA, USA). The insect bioassay data were evaluated in the statistical software "R" version 3.1.2 (http://www.r-proje ct.org). We used the significance levels of 5 and $1 \%$ in all statistical analyses.

\section{Results}

\section{Olfactometer assays with melon plants}

The wasps' first choice (Fig. 1a, binomial test, $N=50$, $P=0.26$ ) and time spent (Fig. 1c, Friedman $\chi^{2}=0, \mathrm{df}=1$, $P=1)$ did not differ in the odor quadrants of blank compared to undamaged melon plants. However, the proportion of wasps entering an olfactometer quarter was higher in arms with undamaged melons than in blank arms (Fig. 1b, binomial test, $N=78, P=0.03$ ).

Females of $E$. desantisi preferred volatile compounds from host-infested melon plants instead of blanks, in their first choice (Fig. 1a, binomial test, $N=50, P=0.02$ ). In addition, the proportion of wasps entering (Fig. 1b, binomial test, $N=133, P<0.001$ ) and the time spent (Fig. 1c, Friedman $\left.\chi^{2}=21.10, \mathrm{df}=3, P<0.001\right)$ in arms with the odor from host-infested melon plants were higher than in blank olfactometer arms.
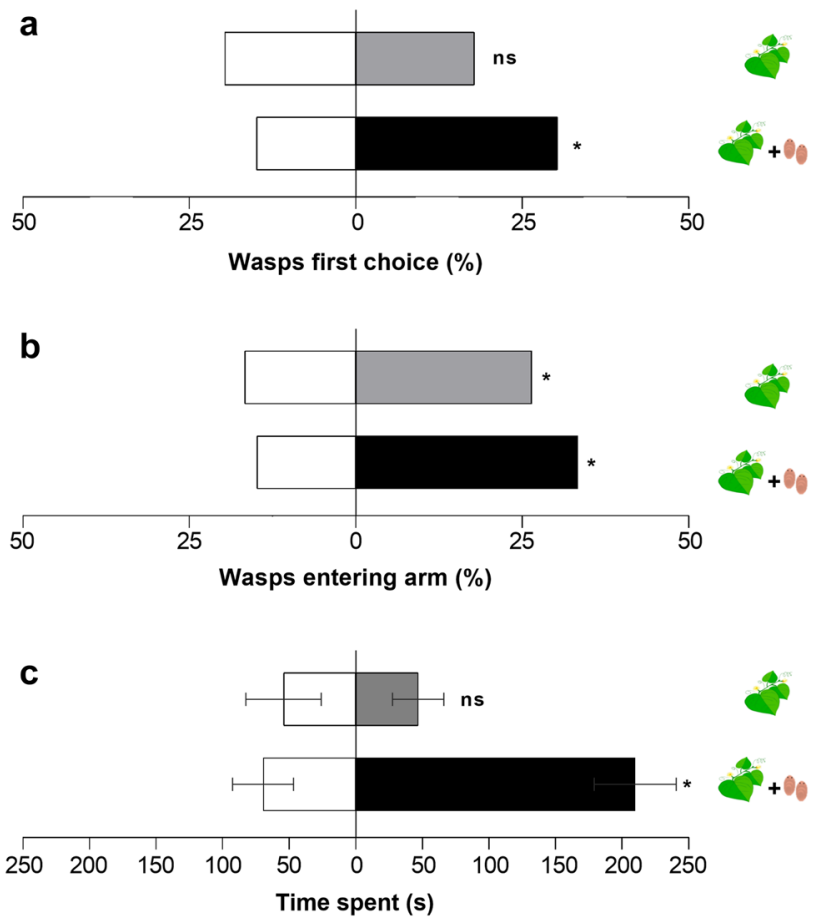

Fig. 1 Preference of the parasitic wasp Encarsia desantisi for blank and flowering-melon volatiles in the four-arm olfactometry assay. Parasitoids' first choice (a), entering arm frequency (b) and time spent (mean \pm SE) (c) in olfactometer quadrants with blank (white bars), volatiles from and undamaged melon (gray bars) or from hostinfested melon plants (black bars). *Designates significant difference at 5\% according to binomial test $(\mathbf{a}, \mathbf{b})$ or according to Friedman's two-way test followed by Wilcoxon's test with Bonferroni's correction for multiple comparisons (c); $n s$ no significant difference

When E. desantisi was exposed to blank, undamaged and infested plants scents at the same time, the wasps' first choice did not differ among treatments (Fig. 2a, multinomial test, $N=50, P>0.14$ ). Nonetheless, wasp entrance (Fig. $2 \mathrm{~b}$, multinomial test, $N=132, P<0.01$ ) and time spent (Fig. $2 \mathrm{c}$, Friedman $\left.\chi^{2}=10.34, \mathrm{df}=3, P=0.01\right)$ in host-infested-odor olfactometer quarters were higher than in blank and undamaged-melon odor quadrants, while the response to undamaged melons did not differ from blank arms $(P>0.56)$.

\section{Melon plant volatiles}

We identified 12 volatile compounds in samples collected over $24 \mathrm{~h}$ from undamaged and host-infested melon plants (Table 1, Online Resource 1). There was no difference in the total amount of volatiles released by the treatments (Fig. 3a, Wilcoxon signed-rank test, $W=12, P=0.39$ ). Considering individual volatiles, the emissions of all compounds did not differ significantly between treatments (Table 1, Wilcoxon signed-rank test, $W>8, P>0.13$ ), except for methyl salicylate and tetradecane, which were released only by 

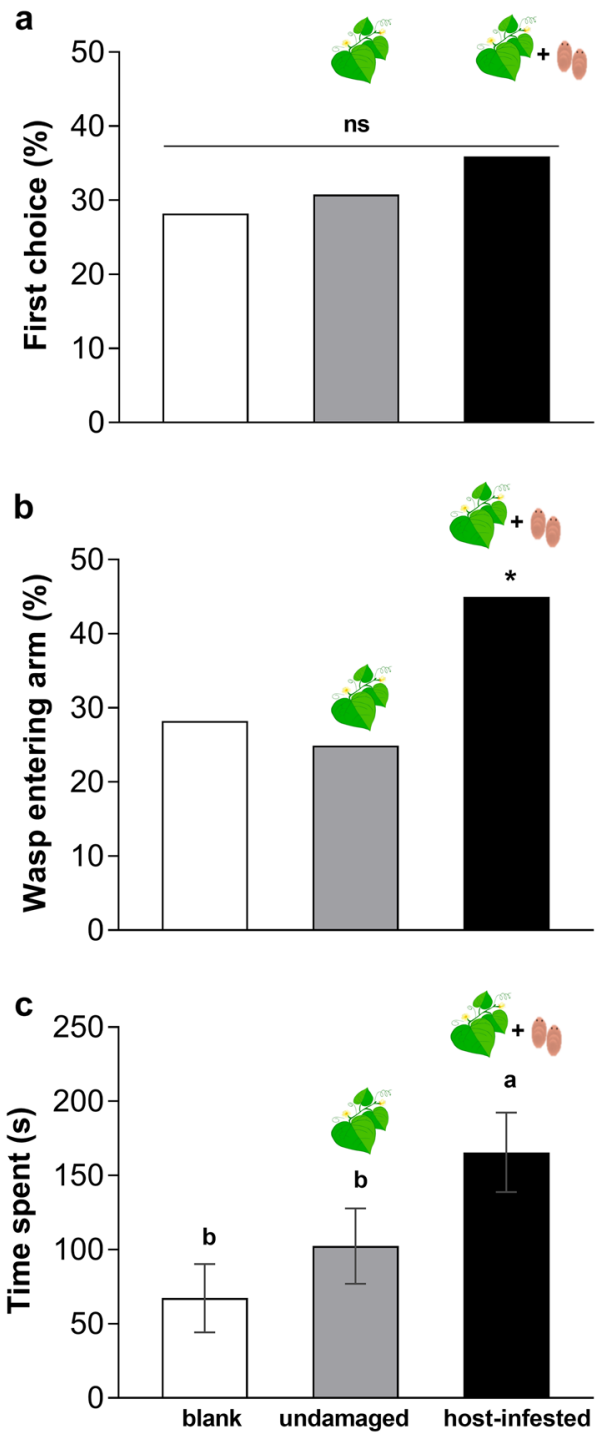

Fig. 2 Preference of the parasitic wasp Encarsia desantisi for different flowering-melon volatiles in the four-arm olfactometry assay. Parasitoids' first choice (a), entering arm frequency (b) and time spent $($ mean $\pm \mathrm{SE})$ (c) in olfactometer quadrants with blank (white bars), volatiles from undamaged melon plants (gray bars) or from host-infested melon plants (black bars). *Designates significant difference at $5 \%$ according to multinomial test; $n s$ no significant difference; same letters do not differ according to Friedman two-way test followed by Wilcoxon's test with Bonferroni's correction for multiple comparisons

host-infested plants (Table 1, Wilcoxon signed-rank test, $W=3, P<0.01$ ).

There were noticeable differences in the emission of individual compounds between the treatments, in spite of a wide variability in emissions. Therefore, when compounds were grouped in chemical classes, the volatile emissions by undamaged and host-infested melon plants did differ quantitatively (Fig. 3b). Host-damaged melon plants released larger amounts of monoterpenes (Fig. 3b, Wilcoxon signed-rank test, $W=2, P=0.03$ ) and alkane (Fig. 3b, Wilcoxon signed-rank test, $W=3, P>0.04$ ), while undamaged plants emitted larger amounts of benzenoids (Fig. 3b, Wilcoxon signed-rank test, $W=0, P<0.01$ ).

Analyses of the volatile composition using PCA for compounds grouped in chemical classes showed that the first component, which comprised $46 \%$ of the variance, separated host-infested from undamaged melon plants (Fig. 4). This was correlated with the abundance of monoterpenes and alkane, in contrast to benzenoids (Fig. 4).

\section{Olfactometer assays with synthetic compounds}

The parasitoid wasps first chose odors from the blend with synthetic compounds, compared to hexane (Fig. 5a, multinomial test, $N=30, P<0.001)$. Furthermore, the wasps spent more time in olfactometer quadrants that contained synthetic volatiles than in quadrants that contained the hexane solvent alone (Fig. 5b, Friedman $\chi^{2}=4.80, \mathrm{df}=1, P=0.02$ ).

\section{Discussion}

Our data showed that $E$. desantisi discriminates melon volatiles from flowering plants, and that the parasitoid attraction is dependent on host-derived cues, similarly to other species of Encarsia (Guerrieri 1997; Birkett et al. 2003; Li et al. 2014). Although the wasps did not spend more time in or first choose olfactometer arms containing odors from undamaged melon plants over blank arms, the entering frequency was higher in the plant-scent quarter, which suggests that $E$. desantisi recognizes volatiles from intact melons. Several other species of parasitic wasps do not display a strong attraction toward undamaged plants (Blassioli Moraes et al. 2005; Tamiru et al. 2011), since reliable information from host location at long distances is generally obtained from wound-induced plants (Bruce et al. 2005; Bruce 2014). Therefore, we then tested the preference of females for blanks over host-infested melon plants. For all parameters evaluated, the parasitic wasps oriented toward the host-damaged plants, indicating that whitefly-related cues are essential to attract $E$. desantisi during its host-searching behavior.

Parasitoids must discriminate among many sources of odors while searching for suitable hosts (Aartsma et al. 2017). We evaluated E. desantisi preferences for blank arms and for volatiles from undamaged and host-infested flowering melon plants. The females oriented equally to all scents at first but entered olfactometer arms with whitefly-induced plants more often and spent more time there. Other Encarsia species, such as E. formosa, engage in random searches in order to find their host (Roermund and Van Lenteren 1995a; Van Lenteren et al. 1996; Sütterlin and Van Lenteren 2000). Once an Encarsia wasp encounters host-associated cues, the 
Table 1 Volatiles compounds emitted by undamaged and hostinfested flowering melons

\begin{tabular}{|c|c|c|c|c|c|}
\hline \multirow[t]{2}{*}{ Compound } & \multirow{2}{*}{$\begin{array}{l}\text { Retention } \\
\text { time (min) }\end{array}$} & \multirow{2}{*}{$\begin{array}{l}\text { Calculated } \\
\text { Kovats Index }\end{array}$} & \multicolumn{2}{|c|}{ ng $100 \mathrm{~g}^{-1}$ of dry plant tissue } & \multirow[t]{2}{*}{$P$ value $^{\mathrm{a}}$} \\
\hline & & & Undamaged & Host-infested & \\
\hline \multicolumn{6}{|l|}{ Monoterpenes } \\
\hline$\alpha$-Pinene & 12.994 & 932.20 & $39.11 \pm 19.21$ & $54.72 \pm 24.52$ & 0.588 \\
\hline Sabinene & 13.956 & 967.47 & $6.96 \pm 3.75$ & $14.72 \pm 5.54$ & 0.240 \\
\hline$\beta$-Pinene & 14.081 & 972.06 & $5.84 \pm 2.42$ & $36.02 \pm 22.83$ & 0.240 \\
\hline$\beta$-Myrcene & 14.576 & 990.21 & $1.97 \pm 1.08$ & $39.94 \pm 22.01$ & 0.294 \\
\hline Ocimene & 15.828 & 1040.27 & $8.17 \pm 6.00$ & $14.16 \pm 6.31$ & 0.132 \\
\hline$\alpha$-Terpineol & 19.000 & 1176.76 & $11.13 \pm 6.47$ & $8.63 \pm 5.28$ & 0.071 \\
\hline \multicolumn{6}{|l|}{ Benzenoids } \\
\hline 3-Phenyl-1-propanal & 16.966 & 1130.37 & $2.07 \pm 1.10$ & $2.69 \pm 2.69$ & 0.245 \\
\hline Methyl salicylate & 17.547 & 1174.38 & $0.00 \pm 0.00$ & $4.55 \pm 3.12$ & 0.009 \\
\hline 3-Phenyl-propanol & 19.628 & 1204.27 & $33.52 \pm 22.74$ & $1.01 \pm 1.01$ & 0.129 \\
\hline Cinnamaldehyde & 20.301 & 1237.99 & $23.77 \pm 16.19$ & $0.51 \pm 0.51$ & 0.182 \\
\hline Cinnamyl alcohol & 21.121 & 1277.78 & $46.61 \pm 36.26$ & $0.85 \pm 0.85$ & 0.462 \\
\hline \multicolumn{6}{|l|}{ Alkane } \\
\hline Tetradecane & 24.009 & 1427.79 & $0.00 \pm 0.00$ & $14.17 \pm 6.70$ & 0.009 \\
\hline
\end{tabular}

Relative amounts (mean $\pm \mathrm{SE}$ ) were estimated based on internal standard

${ }^{a}$ Highlighted $P$ value $(P<0.05)$ indicates significant differences between treatments according to Wilcoxon signed rank test
Fig. 3 Composition of melon volatiles released by undamaged and host-infested melon plants. Total amount of volatiles emitted (mean \pm SE) (a) and compounds released according to volatile chemical classes (mean \pm SE) (b). *Designates significant difference at $5 \%$ according to Wilcoxon signedrank test; $n s$ no significant difference a

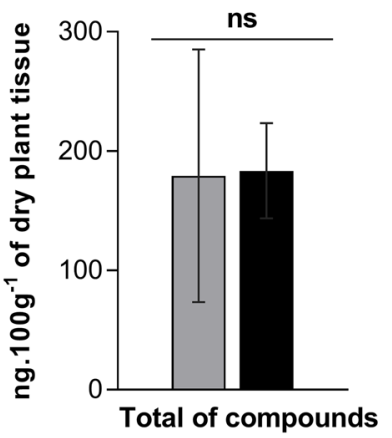

b

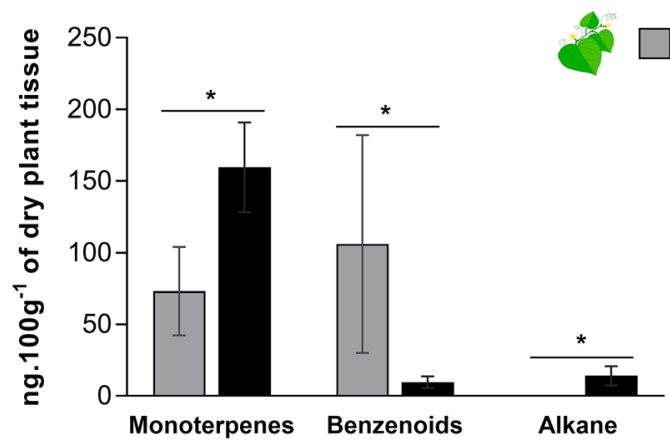

Host-infested Undamaged

of the whitefly B. tabaci (Walling 2008). MeSa is widely employed by predators and parasitoids during host-finding behavior (Zhu and Park 2005; Mallinger et al. 2011), and the use of synthetic lures containing this compound has proved to be efficient in monitoring and recruiting natural enemies in several fruit crops (James 2003b; James and Price 2004; Rodriguez-Saona et al. 2011). Conversely, the alkane tetradecane found in whitefly-infested plants might be derived from the plant, the whiteflies, or both. In some species, tetradecane occurs in volatile blends from both undamaged and host-infested plants in some species (Liu et al. 2009), although after early wound induction it can be emitted at higher rates by insect-damaged plants (Lou et al. 2005). Tetradecane may also be a kairomone cue for natural enemies, since the feces of some insect species contain this alkane (Steidle et al. 2003) and result in 


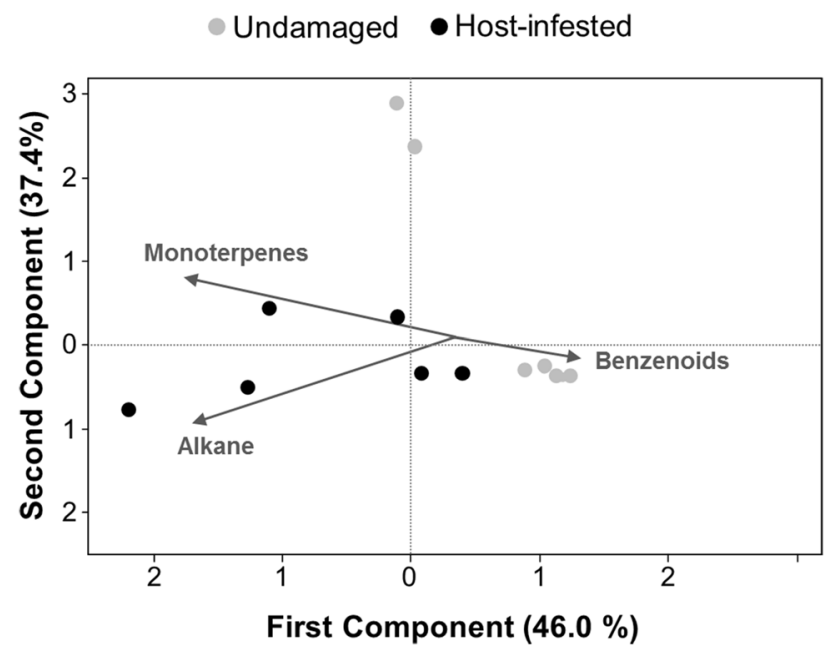

Fig. 4 Loading plots for principal components analysis (PCA) with plant-volatile chemical classes as variables. PCA of composition of volatiles emitted by undamaged and host-infested melon plants according to compound chemical classes

an intense olfactory activity of egg parasitoids (Morawo et al. 2016).

Similarly, to most of the individual compounds, the total volatiles released by undamaged and host-infested flowering melons did not differ statistically. Unlike tissue-damaging herbivores, phloem-feeders stimulate the emission of smaller quantities of volatiles compared to intact plants, and at times no changes may be detectable (Du et al. 1998; Turlings et al. 1998; Rodriguez-Saona et al. 2003; Silva et al. 2017), due to the minimal leaf injury inflicted and to salivary effectors that prevent the synthesis of volatiles (Walling 2008). Although Desurmont et al. (2015) showed that herbivory induces much smaller amounts of leaf volatiles in flowering than in vegetative plant stages, parasitic wasps are still able to recognize nuances of plant-blend composition in order to effectively locate their host (Bruce et al. 2005).

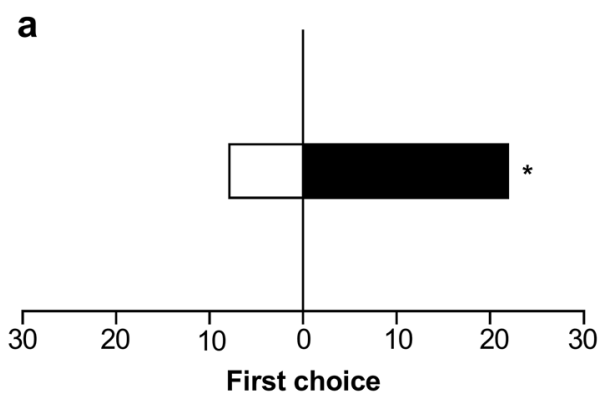

Fig. 5 Preference of the parasitic wasp Encarsia desantisi for blends of synthetic volatiles and hexane in four-arm olfactometry assay. Parasitoids' first choice (a) and time spent (mean \pm SE) (b) in olfactometer quadrants with hexane or synthetic volatiles mimicking host-
We therefore grouped plant volatiles in chemical classes, in order to investigate potential qualitative differences between undamaged and whitefly-infested flowering-melon volatiles that mediate the preference of $E$. desantisi. The alkane class consisted only of tetradecane, which was emitted only in whitefly-induced melons. Interestingly, whitefly feeding reduced benzenoid emissions at the same time that it increased the release of monoterpenes. In consequence, the high levels of terpenoids might underlie the preference of $E$. desantisi parasitoids for host-infested plants, as they do for most natural enemies (Degenhardt et al. 2003; Kappers et al. 2005).

Since several benzenoids are flowering-related volatiles (Dudareva et al. 2004; Vogt 2010) and moterpenes are mostly defense-related volatiles (Dudareva et al. 2013), we speculate whether the phloem-feeding of whiteflies would cause a trade-off between reproduction and defense in flowering melon plants. Volatile shifting may be the primary paradigm in plant biology, which is the allocation of resources, since energy devoted to defense is unavailable for reproduction and vice versa (Herms and Mattson 1992; LucasBarbosa et al. 2011; Lucas-Barbosa 2016). Few studies have described defense and reproduction trade-off mechanisms induced by phloem-feeding insects in flowering plants, their effects on third-trophic-level interactions (Hare 2010; LucasBarbosa et al. 2011; Lucas-Barbosa 2016). The reproductive effect of whitefly feeding on melon plants is beyond the scope of this study, but our analyses of volatiles grouped by chemical classes could indicated that intense feeding of B. tabaci nymphs, which reduces the plant phloem content (Stansly and Naranjo 2010), also reduced the flower compounds and simultaneously increased the defenses that make a plant highly attractive to parasitoids. Further investigations are required to clarify the defenses strategies of melon plants throughout their ontogeny, which would include comparisons of the emission of volatiles compounds in all vegetative and reproductive stages, before and after $B$. tabaci attack.

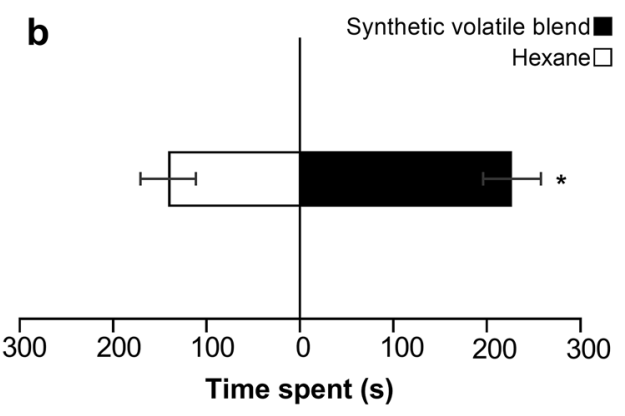

infested plant. *Designates significant difference at 5\% according to binomial test for first choice or Friedman two-way test followed by Wilcoxon's test with Bonferroni's correction for multiple comparisons 
Based on the preference of $E$. desantisi, we selected the most quantitatively important terpenes and alkane, in order to mimic the defensive compounds of host-infested flowering melon plants that attracted the parasitoids. We produced a mix of synthetic compounds comprised the monoterpenes $\alpha$-pinene, $\beta$-pinene, $\beta$-myrcene, and $\beta$-ocimene, the benzenoid MeSa, and the alkane tetradecane. The wasps first chose and spent more time in the mix of volatiles than in the hexane-solvent odor areas, indicating a strong preference for the mimic scent. Previous studies have shown that hymenopteran parasitoids are attracted by a wide range of synthetic volatiles, both in laboratory assays (Birkett et al. 2003; Lou et al. 2005; Bruinsma et al. 2009; Li et al. 2014) and as field lures (James 2003a, b; James and Grasswitz 2005). Since specialist parasitoids are more discriminatory in exploiting HIPVs than are generalist parasitoids (McCormick et al. 2012), the adoption of synthetic lures that best mimic the complex volatile blend of host-infested plants is more likely to efficiently recruit parasitic wasps. Furthermore, specialist parasitoids extensively employ plant volatiles as valuable cues to locate hosts at a suitable stage of development for parasitism (Takabayashi et al. 1995; Yoneya et al. 2009). Thus, lures that release volatiles closely associated with specific host damage at the ideal stage of development for parasitism, such as our synthetic blend tested on E. desantisi in flowering melon plants, would be even more effective in recruiting and monitoring natural enemies, helping in biological-control strategies (Kaplan 2012).

In summary, we found that the whitefly $B$. tabaci induces the emission of different volatile blends in infested compared to undamaged flowering melon plants. Although the amount of volatiles and the majority of individual compounds did not differ between the two plant treatments, only the host-infested melons released MeSa and tetradecane, compounds known to attract natural enemies. In addition, whitefly-infested flowering melon plants displayed a tradeoff between defensive and reproductive volatiles, emitting high amounts of monoterpenes and alkane and reducing the release of benzenoids. The parasitoid E. desantisi recognized volatiles from undamaged flowering melons; however, these wasps strongly preferred the odor of infested flowering plants. Additionally, the wasps were attracted to the mix of synthetic defensive volatiles that mimicked whitefly-infested flowering melons, opening a new avenue for further investigations on the use of olfactory lures in the biological control of $B$. tabaci. To the best of our knowledge, this is the first report of induced defenses in melon plants and melon volatiles mediating a tritrophic interaction. This is also the first study to evaluate the use of plant volatiles by $E$. desantisi parasitoids during their host-searching behavior.

Acknowledgements The authors acknowledge financial support from the National Institute of Science and Technology (INCT)
Semiochemicals in Agriculture (Conselho Nacional de Desenvolvimento Científico e Tecnológico-CNPq, Process 465511/2014-7, and the Fundação de Amparo à Pesquisa do Estado de São PauloFAPESP, Process 2014/50871-0). TAS was funded by the Coordenação de Aperfeiçoamento de Pessoal de Nível Superior (CAPES) and PAS by FAPESP, (Process 2017/18226-6).

\section{Compliance with ethical standards}

Conflict of interest All the authors confirm that they have no financial or other involvement in activities or organizations that might bias the work reported here.

\section{References}

Aartsma Y, Bianchi FJ, Werf W, Poelman EH, Dicke M (2017) Herbivore-induced plant volatiles and tritrophic interactions across spatial scales. New Phytol 216:1054-1063. https://doi.org/10.1111/ nph. 14475

Arnó J, Gabarra R, Liu T-X, Simmons AM, Gerling D (2009) Natural enemies of Bemisia tabaci: predators and parasitoids. In: Stansly PA, Naranjo SE (eds) Bemisia: bionomics and management of a global pest. Springer, Netherlands, pp 385-421

Birkett M, Chamberlain K, Guerrieri E, Pickett J, Wadhams L, Yasuda $\mathrm{T}$ (2003) Volatiles from whitefly-infested plants elicit a host-locating response in the parasitoid, Encarsia formosa. J Chem Ecol 29:1589-1600. https://doi.org/10.1023/A:102421872

Blassioli Moraes MC, Laumann R, Sujii ER, Pires C, Borges M (2005) Induced volatiles in soybean and pigeon pea plants artificially infested with the neotropical brown stink bug, Euschistus heros, and their effect on the egg parasitoid, Telenomus podisi. Entomol Exp Appl 115:227-237. https://doi.org/10.111 1/j.1570-7458.2005.00290.x

Boege K, Marquis RJ (2005) Facing herbivory as you grow up: the ontogeny of resistance in plants. Trends Ecol Evo 20:441-448. https://doi.org/10.1016/j.tree.2005.05.001

Boege K, Dirzo R, Siemens D, Brown P (2007) Ontogenetic switches from plant resistance to tolerance: minimizing costs with age? Ecol Lett 10:177-187. https://doi.org/10.111 1/j.1461-0248.2006.01012.x

Bonaventure G (2014) Plants recognize herbivorous insects by complex signalling networks. Annu Plants Rev 47:1-35. https://doi. org/10.1002/9781118829783.ch1

Bruce TJ (2014) Interplay between insects and plants: dynamic and complex interactions that have coevolved over millions of years but act in milliseconds. J Exp Bot 66:455-465. https://doi. org/10.1093/jxb/eru391

Bruce TJ, Wadhams LJ, Woodcock CM (2005) Insect host location: a volatile situation. Trends Plant Sci 10:269-274. https://doi. org/10.1016/j.tplants.2005.04.003

Bruinsma M, Posthumus MA, Mumm R, Mueller MJ, Van Loon JJ, Dicke M (2009) Jasmonic acid-induced volatiles of Brassica oleracea attract parasitoids: effects of time and dose, and comparison with induction by herbivores. J Exp Bot 60:2575-2587. https:// doi.org/10.1093/jxb/erp101

De Vis RM, Mendez H, Van Lenteren JC (2003) Comparison of foraging behavior, interspecific host discrimination, and competition of Encarsia formosa and Amitus fuscipennis. J Insect Behav 16:117-152. https://doi.org/10.1023/A:1022805529942

Degenhardt J, Gershenzon J, Baldwin IT, Kessler A (2003) Attracting friends to feast on foes: engineering terpene emission to make crop plants more attractive to herbivore enemies. Curr 
Opin Biotechnol 14:169-176. https://doi.org/10.1016/S0958 $-1669(03) 00025-9$

Desurmont GA, Laplanche D, Schiestl FP, Turlings TC (2015) Floral volatiles interfere with plant attraction of parasitoids: ontogenydependent infochemical dynamics in Brassica rapa. BMC Ecol 15:17. https://doi.org/10.1186/s12898-015-0047-7

Du Y, Poppy GM, Powell W, Pickett JA, Wadhams LJ, Woodcock CM (1998) Identification of semiochemicals released during aphid feeding that attract parasitoid Aphidius ervi. J Chem Ecol 24:1355-1368. https://doi.org/10.1023/A:1021278816970

Dudareva N, Pichersky E (2006) Biology of floral scent. CRC Press, Boca Raton

Dudareva N, Pichersky E, Gershenzon J (2004) Biochemistry of plant volatiles. Plant Physiol 135:1893-1902. https://doi.org/10.1104/ pp.104.049981

Dudareva N, Klempien A, Muhlemann JK, Kaplan I (2013) Biosynthesis, function and metabolic engineering of plant volatile organic compounds. New Phytol 198:16-32

Erb M, Meldau S, Howe GA (2012) Role of phytohormones in insectspecific plant reactions. Trends Plant Sci 17:250-259. https://doi. org/10.1111/nph.12145

Guerrieri E (1997) Flight behaviour of Encarsia formosa in response to plant and host stimuli. Entomol Exp Appl 82:129-133. https:// doi.org/10.1046/j.1570-7458.1997.00122.x

Gurr G, Kvedaras O (2010) Synergizing biological control: scope for sterile insect technique, induced plant defences and cultural techniques to enhance natural enemy impact. Biol Control 52:198207. https://doi.org/10.1016/j.biocontrol.2009.02.013

Hare JD (2010) Ontogeny and season constrain the production of herbivore-inducible plant volatiles in the field. J Chem Ecol 36(12):1363-1374. https://doi.org/10.1007/s10886-010-9878-z

Heil M (2009) Damaged-self recognition in plant herbivore defence. Trends Plant Sci 14:356-363. https://doi.org/10.1016/j.tplan ts.2009.04.002

Heraty JM, Polaszek A, Schauff ME (2008) Systematics and biology of Encarsia. In: Gould J, Hoelmer KA, Golsby JA (eds) Classical biological control of Bemisia tabaci in the United States: a review of interagency research and implementation. Springer, Amsterdam, pp 71-87

Herms DA, Mattson WJ (1992) The dilemma of plants: to grow or defend. Q Rev Biol 67:283-335. https://doi.org/10.1086/417659

Hoddle M, Van Driesche R, Sanderson J (1998) Biology and use of the whitefly parasitoid Encarsia formosa. Annu Rev Entomol 43:645-669. https://doi.org/10.1146/annurev.ento.43.1.645

James DG (2003a) Synthetic herbivore-induced plant volatiles as field attractants for beneficial insects. Environ Entomol 32:977-982. https://doi.org/10.1603/0046-225X-32.5.977

James DG (2003b) Field evaluation of herbivore-induced plant volatiles as attractants for beneficial insects: methyl salicylate and the green lacewing, Chrysopa nigricornis. J Chem Ecol 29:1601-1609. https://doi.org/10.1023/A:1024270713493

James DG, Grasswitz TR (2005) Synthetic herbivore-induced plant volatiles increase field captures of parasitic wasps. Biocontrol 50:871-880. https://doi.org/10.1007/s10526-005-3313-3

James DG, Price TS (2004) Field-testing of methyl salicylate for recruitment and retention of beneficial insects in grapes and hops. J Chem Ecol 30:1613-1628. https://doi.org/10.1023/ B:JOEC.0000042072.18151.6f

Jones VP et al (2015) Evaluating plant volatiles for monitoring natural enemies in apple, pear and walnut orchards. Biol Control 102:5365. https://doi.org/10.1016/j.biocontrol.2015.03.009

Kaplan I (2012) Attracting carnivorous arthropods with plant volatiles: the future of biocontrol or playing with fire? Biol Control 60:77-89. https://doi.org/10.1016/j.biocontrol.2011.10.017

Kappers IF, Aharoni A, Van Herpen TW, Luckerhoff LL, Dicke M, Bouwmeester HJ (2005) Genetic engineering of terpenoid metabolism attracts bodyguards to Arabidopsis. Science 309:2070-2072. https://doi.org/10.1126/science.1116232

Kelly JL, Hagler JR, Kaplan I (2014) Semiochemical lures reduce emigration and enhance pest control services in open-field predator augmentation. Biol Control 71:70-77. https://doi. org/10.1016/j.biocontrol.2014.01.010

Kessler A, Halitschke R (2009) Testing the potential for conflicting selection on floral chemical traits by pollinators and herbivores: predictions and case study. Funct Ecol 23:901-912. https://doi. org/10.1111/j.1365-2435.2009.01639.x

Kessler A, Heil M (2011) The multiple faces of indirect defences and their agents of natural selection. Funct Ecol 25:348-357. https ://doi.org/10.1111/j.1365-2435.2010.01818.x

Khan ZR, James DG, Midega CA, Pickett JA (2008) Chemical ecology and conservation biological control. Biol Control 45:210 224. https://doi.org/10.1016/j.biocontrol.2007.11.009

Koo AJ, Howe GA (2009) The wound hormone jasmonate. Phytochemistry 70:1571-1580. https://doi.org/10.1016/j.phyto chem.2009.07.018

Li SJ et al (2011) Host plants and natural enemies of Bemisia tabaci (Hemiptera: Aleyrodidae) in China. Insect Sci 18:101-120. https://doi.org/10.1111/j.1744-7917.2010.01395.x

Li SJ et al (2014) Efficiency of plant induced volatiles in attracting Encarsia formosa and Serangium japonicum, two dominant natural enemies of whitefly Bemisia tabaci in China. Pest Manag Sci 70:1604-1610. https://doi.org/10.1002/ps.3749

Liu Y, Wang WL, Guo GX, Ji XL (2009) Volatile emission in wheat and parasitism by Aphidius avenae after exogenous application of salivary enzymes of Sitobion avenae. Entomol Exp Appl 130:215-221. https://doi.org/10.1111/j.1570-7458.2008.00822 . $\mathrm{X}$

Liu TX, Stansly PA, Gerling D (2015) Whitefly parasitoids: distribution, life history, bionomics, and utilization. Annu Rev Entomol 60:273-292. https://doi.org/10.1146/annurev-ento-010814-02110 1

Lou YG, Ma B, Cheng JA (2005) Attraction of the parasitoid Anagrus nilaparvatae to rice volatiles induced by the rice brown planthopper Nilaparvata lugens. J Chem Ecol 31:2357-2372. https://doi. org/10.1007/s10886-005-7106-z

Lucas-Barbosa D (2016) Integrating studies on plant—pollinator and plant-herbivore interactions. Trends Plant Sci 21:125-133. https ://doi.org/10.1016/j.tplants.2015.10.013

Lucas-Barbosa D, Van Loon JJ, Dicke M (2011) The effects of herbivore-induced plant volatiles on interactions between plants and flower-visiting insects. Phytochemistry 72:1647-1654. https://doi. org/10.1016/j.phytochem.2011.03.013

Mallinger RE, Hogg DB, Gratton C (2011) Methyl salicylate attracts natural enemies and reduces populations of soybean aphids (Hemiptera: Aphididae) in soybean agroecosystems. J Econ Entomol 104:115-124. https://doi.org/10.1603/EC10253

McCall AC, Fordyce JA (2010) Can optimal defence theory be used to predict the distribution of plant chemical defences? J Ecol 98:985-992. https://doi.org/10.1111/j.1365-2745.2010.01693.x

McCormick AC, Unsicker SB, Gershenzon J (2012) The specificity of herbivore-induced plant volatiles in attracting herbivore enemies. Trends Plant Sci 17:303-310. https://doi.org/10.1016/j.tplan ts.2012.03.012

Morawo T, Burrows M, Fadamiro H (2016) Electroantennogram response of the parasitoid, Microplitis croceipes to host-related odors: the discrepancy between relative abundance and level of antennal responses to volatile compound. F1000Res 5:2725. https ://doi.org/10.12688/f1000research.10104.2

Ohnmeiss TE, Baldwin IT (2000) Optimal defense theory predicts the ontogeny of an induced nicotine defense. Ecology 81:1765-1783. https://doi.org/10.1890/0012-9658(2000)081\%5B1765:ODTPT O\%5D2.0.CO;2 
Pareja M et al (2012) Herbivory by a phloem-feeding insect inhibits floral volatile production. PLoS ONE 7:e31971. https://doi. org/10.1371/journal.pone.0031971

Rodriguez-Saona C, Crafts-Brandner SJ, Cañas LA (2003) Volatile emissions triggered by multiple herbivore damage: beet armyworm and whitefly feeding on cotton plants. J Chem Ecol 29:2539-2550. https://doi.org/10.1023/A:1026314102866

Rodriguez-Saona C, Kapla I, Braasch J, Chinnasamy D, Williams L (2011) Field responses of predaceous arthropods to methyl salicylate: a meta-analysis and case study in cranberries. Biol Control 59(2):294-303

Roermund HV, Van Lenteren J (1995a) Foraging behaviour of the whitefly parasitoid Encarsia formosa on tomato leaflets. Entomol Exp Appl 76:313-324. https://doi.org/10.1111/j.1570-7458.1995. tb01975.x

Roermund HV, Van Lenteren J (1995b) Residence times of the whitefly parasitoid Encarsia formosa Gahan (Hym., Aphelinidae) on tomato leaflets. J Appl Entomol 119:465-471. https://doi. org/10.1111/j.1439-0418.1995.tb01319.x

Schiestl FP, Kirk H, Bigler L, Cozzolino S, Desurmont GA (2014) Herbivory and floral signaling: phenotypic plasticity and tradeoffs between reproduction and indirect defense. New Phytol 203:257266. https://doi.org/10.1111/nph.12783

Silva DB, Weldegergis BT, Van Loon JJ, Bueno VH (2017) Qualitative and quantitative differences in herbivore-induced plant volatile blends from tomato plants infested by either Tuta absoluta or Bemisia tabaci. J Chem Ecol 43:53-65. https://doi.org/10.1007/ s10886-016-0807-7

Stansly PA, Naranjo SE (2010) Bemisia: bionomics and management of a global pest. Springer, Netherlands

Steidle JL, Steppuhn A, Ruther J (2003) Specific foraging kairomones used by a generalist parasitoid. J Chem Ecol 29:131-143. https:// doi.org/10.1023/A:1021932731350

Sütterlin S, Van Lenteren J (2000) Pre-and post-landing response of the parasitoid Encarsia formosa to whitefly hosts on Gerbera jamesonii. Entomol Exp Appl 96:299-307. https://doi.org/10.1 046/j.1570-7458.2000.00709.x

Takabayashi J, Takahashi S, Dicke M, Posthumus M (1995) Developmental stage of herbivore Pseudaletia separata affects production of herbivore-induced synomone by corn plants. J Chem Ecol 21:273-287. https://doi.org/10.1007/BF02036717

Tamiru A et al (2011) Maize landraces recruit egg and larval parasitoids in response to egg deposition by a herbivore. Ecol Lett 14:1075-1083. https://doi.org/10.1111/j.1461-0248.2011.01674.x

Thaler JS, Farag MA, Paré PW, Dicke M (2002) Jasmonate-deficient plants have reduced direct and indirect defences against herbivores. Ecol Lett 5:764-774. https://doi.org/10.104 6/j.1461-0248.2002.00388.x

Turlings TC, Wäckers F (2004) Recruitment of predators and parasitoids by herbivore-injured plants. In: Cardé RT, Millar JG (eds)
Advances in insect chemical ecology, 2nd edn. Cambridge University Press, Cambridge, pp 21-75

Turlings TC, Bernasconi M, Bertossa R, Bigler F, Caloz G, Dorn S (1998) The induction of volatile emissions in maize by three herbivore species with different feeding habits: possible consequences for their natural enemies. Biol Control 11:122-129. https ://doi.org/10.1006/bcon.1997.0591

Van Lenteren JC, Van Roermund HJ, Sütterlin S (1996) Biological control of Greenhouse Whitefly (Trialeurodes vaporariorum) with the Parasitoid Encarsia formosa: How does it work? Biol Control 6:1-10. https://doi.org/10.1006/bcon.1996.0001

Vogt T (2010) Phenylpropanoid biosynthesis. Mol Plant 3:2-20. https ://doi.org/10.1093/mp/ssp106

Walling LL (2008) Avoiding effective defenses: strategies employed by phloem-feeding insects. Plant Physiol 146:859-866. https://doi. org/10.1104/pp.107.113142

Wasternack C, Hause B (2013) Jasmonates: biosynthesis, perception, signal transduction and action in plant stress response, growth and development. An update to the 2007 review in Annals of Botany. Ann Bot 111:1021-1058. https://doi.org/10.1093/aob/mct067

Yoneya K, Kugimiya S, Takabayashi J (2009) Can herbivore-induced plant volatiles inform predatory insect about the most suitable stage of its prey? Physiol Entomol 34:379-386. https://doi.org/1 0.1111/j.1365-3032.2009.00701.x

Yu H, Zhang Y, Wu K, Gao XW, Guo YY (2008) Field-testing of synthetic herbivore-induced plant volatiles as attractants for beneficial insects. Environ Entomol 37:1410-1415. https://doi. org/10.1603/0046-225X-37.6.1410

Zarate SI, Kempema LA, Walling LL (2007) Silverleaf whitefly induces salicylic acid defenses and suppresses effectual jasmonic acid defenses. Plant Physiol 143:866-875. https://doi.org/10.1104/ pp.106.090035

Zhang P-J, Li W-D, Huang F, Zhang J-M, Xu F-C, Lu Y-B (2013a) Feeding by whiteflies suppresses downstream jasmonic acid signaling by eliciting salicylic acid signaling. J Chem Ecol 39:612619. https://doi.org/10.1007/s10886-013-0283-2

Zhang PJ et al (2013b) Phloem-feeding whiteflies can fool their host plants, but not their parasitoids. Funct Ecol 27:1304-1312. https ://doi.org/10.1111/1365-2435.12132

Zhu J, Park KC (2005) Methyl salicylate, a soybean aphid-induced plant volatile attractive to the predator Coccinella septempunctata. J Chem Ecol 31:1733-1746. https://doi.org/10.1007/s1088 6-005-5923-8

Zilahi-Balogh G, Shipp J, Cloutier C, Brodeur J (2009) Comparison of searching behaviour of two aphelinid parasitoids of the Greenhouse Whitefly, Trialeurodes vaporariorum under summer vs. winter conditions in a temperate climate. J Insect Behav 22:134147. https://doi.org/10.1007/s10905-008-9160-1 